Abstract

\title{
Entropy in Software Architecture ${ }^{+}$
}

\section{Stanisław Jerzy Niepostyn}

Warsaw University of Technology, Warszawa, Poland

+ Presented at the Entropy 2021: The Scientific Tool of the 21st Century, 5-7 May 2021; Available online: https://sciforum.net/conference/Entropy2021/.

Published: 5 May 2021

In building software architectures, the relations between elements in different diagrams are often overlooked. When constructing software architecture, IT architects more or less consciously however introduce elements that represent the same object instance on different diagrams with similar names. These connections are called consistency rules and are usually not saved in any way in the modeling tool. It was mathematically proved that the application of consistency rules increases the information content of software architecture. The feelings about increasing readability and ordering of software architecture by means of consistency rules have their mathematical rationale. In this article it was carried out a proof of decreasing information entropy while applying consistency rules in the construction of software architecture of IT systems. Therefore, it has been shown that marking selected elements in different diagrams with similar names is therefore an implicit way to increase the information content of software architecture while simultaneously improving its orderliness and readability.

(C) 2021 by the author. Licensee MDPI, Basel, Switzerland. This article is an open access article distributed under the terms and conditions of the Creative Commons Attribution (CC BY) license (http://creativecommons.org/licenses/by/4.0/). 